\title{
College Mathematics Teaching Method Based on Big Data
}

\author{
$\underline{\text { https://doi.org/10.3991/ijet.v14i13.10708 }}$
}

Limin Cui, Yonglong Liao $\left.{ }^{(}\right)$, Ying Wang, Xiaoyan Dong

Beijing Institute of Petrochemical Technology, Beijing, China

liaoyonglong@bipt.edu.cn

\begin{abstract}
With the aid of big data technology, this paper enumerates the existing problems of college mathematics teaching, and designs a big databased method for mathematics teaching among college students. The studentcentered design method highlights the evaluation of learning effects, making both teaching and learning more efficient. The method was applied to the teaching reform in an actual college and achieved good results. The research findings shed new light on the mathematics teaching and learning in colleges.
\end{abstract}

Keywords—Big data, mathematics, teaching design, evaluation

\section{Introduction}

With the rapid development of information technology, the world has entered the era of big data. As a scientific impetus to change the world, it is influencing all walks of life, and the education industry is no exception. Massive data is gradually integrated into education and teaching, with these data and information, we can better serve the education and the teaching. The transformation of teaching concepts and teaching ideas in the era of big data will inevitably lead to the reform of teaching modes and teaching methods. "Student-centered" will no longer be an empty slogan, truly understand every student and their needs is the basic quality for a college mathematics teacher. How to make full use of the big data analysis to correct problems existing in traditional college mathematics teaching, optimize and perfect the process of teachers' teaching and students' learning, evaluate the students' learning effects, and explore and discuss the reform of college mathematics teaching based on big data analysis is the main research content of this paper.

Big data refers to a massive and complex collection of data that contains valid information values but is not easily mined, managed, or processed. There are four main characteristics of big data: Volume, Variety, Velocity, and Veracity. Big data analysis can obtain and use comprehensive data, complete data and system data in various fields. Through artificial intelligence and data mining methods, we can mine and extract useful information from massive data, deeply explore the laws of the real world, and acquire knowledge that was not available in the past [1]. Big data is strongly affecting the entire education system and has become a new force to promote 
the reform of education modes and methods. Education big data is a subset of big data, it's generated in the education field, and it's a collection of data generated with the on-going educational activities. The education big data is mainly composed of two parts: the teachers' teaching and the students' learning [2], such as the data of teachers' teaching activities, the data of teachers' classroom management, the data of students' learning behaviors, and the data of the teaching effects, etc. These data can include both procedural data and outcome data. Educators can find their relevant relationships from the massive and complex data, observe the nature of teaching and learning from multiple dimensions, discover the problems existing in education, and predict the development trend, so as to promote the fairness of education and realize individualized teaching, which provides a new direction for the reform of teaching [38].

Before the emergence of big data, traditional education data collection is often staged and occurs under the condition that the teachers and students are prepared. These data can only be analyzed by means of sampling, and the laws of unknown fields are explored even by experiences, theories, hypotheses or values. Therefore, people's perception of education is sometimes superficial and simple. Compared with traditional education data, the education big data is the data collected under the condition that teachers and students are in a natural state, such as the feedback from students after a certain knowledge point is explained by the teacher. These data no longer depend on algorithms or models, but instead allow the data to speak for itself. Instead of sticking to the causal relationship between the data, correlation analysis is performed on the data, so that educators are able to explore and analyze the data that was previously unable to be analyzed by techniques or methods in the vast amounts of data. We try to solve the problem of education big data by using methods such as statistics, machine learning and data mining, so as to better understand the learning quality of students and improve the level of education management decision-making [9-11].

The main roles of education big data in education and teaching are:

- Education big data enables teachers to instantly understand the learning needs of all students, so that teachers can shift their role from the knowledge provider to the designer of teaching and learning, and evaluate the teaching effects from multiple angles and realize individualized teaching;

- The analysis and mining of education big data enable educators to discover potential problems and predict the effectiveness of education and teaching.

- Education big data can break the traditional experience-based teaching management mode, and carry out quantitative management decision-making, which has important guiding significance for the schools' education and teaching management and decision-making, as well as provides data support.

In short, education big data can promote the synergistic progress of teaching and learning, greatly promote the reform of education and teaching, as well as the scientization of educational decisions [12-13]. 


\section{Problems in College Mathematics Teaching}

College mathematics usually includes courses of Advanced Mathematics, Linear Algebra, Probability Theory and Mathematical Statistics, etc. These courses are the core courses of basic quality training in higher education, and also the source of motivation for students to continue their studies and innovation. Although the teaching research and exploration for college mathematics is very common, and many achievements and experiences had been summarized from practice, many problems in college mathematics teaching in our country have not been solved fundamentally yet.

\subsection{Students lack of subjective initiative for learning}

College mathematics has the characteristics of more content and less class hours. Its traditional teaching method is that teachers explain the textbooks in the classroom, sometimes with the help of multimedia technology, but they only use the multimedia courseware to display conceptual and conclusive content, and use the blackboard writing to analyze the mathematics ideas and processes. Although students realize the usefulness and importance of college mathematics courses, they can only listen to the lecture passively, lacking the objective environment to participate in the teaching process in a dominant position, which cannot effectively promote the students' subjective initiative.

\subsection{Students' learning emphasizes results over procedures}

The content of college mathematics is abstract and difficult to understand. For some students, although they can recite the mathematic concepts, they could not understand them, and unable to master the ideas or methods to solve college mathematics problems. The main reason is that most of these students learn passively, they only prepare the lessons before class occasionally, and only study hard before the exams; there's no effective supervision mechanism for the students' procedural learning, which results in that the students' learning emphasizes results over procedures.

\subsection{Teachers pay less attention to students' learning effects}

In traditional teaching, teachers are more concerned with the teaching effects of the teachers than the learning effects of the students. Therefore, in the college mathematics classroom, we can usually see the scene that teachers talk all through the classroom time, and the interaction is often limited to questions and answers. Whether students really understand and master the knowledge and whether they can think independently are often neglected, and the classroom presents a characteristic of teacher dominate and students come second. Most of the current teaching evaluation system is based on the teacher's teaching, and lacks evaluation of the students' learning effects. 


\subsection{Insufficient implementation of college teaching reform practice based on education big data}

For many colleges and universities, the integration of education big data and educational teaching still stays at the conceptual level, and hasn't been fully implemented into classroom teaching yet. Even though some colleges and universities have combined college mathematics curriculum with education big data, the overall application ability of teachers and the analytical ability of teaching managers are also seriously inadequate, and they cannot effectively use these data to analyze and improve the teaching situations.

\section{College Mathematics Teaching Design Based on Big Data Analysis}

\subsection{Framework of teaching design}

The college mathematics teaching design proposed in this paper is shown in Figure 1. Teachers' teaching behavior data (such as publishing teaching resources and test questions, Q\&A, etc.) and the students' learning behavior data (such as viewing resources, doing test questions, raising questions online, etc.) will be stored in the digital form; teachers present the teaching content on the intelligent teaching platform (e.g. the Blackboard) in the forms of texts, pictures, audios, videos, and online resource push. When instructors and learners are using the intelligent teaching platform, their "teaching" and "learning" data will be stored on the platform; the intelligent teaching platform is not only the carrier of the teaching content, but also the collection terminal and the transmission channel of education big data, moreover, it provides supports for the running of education big data.

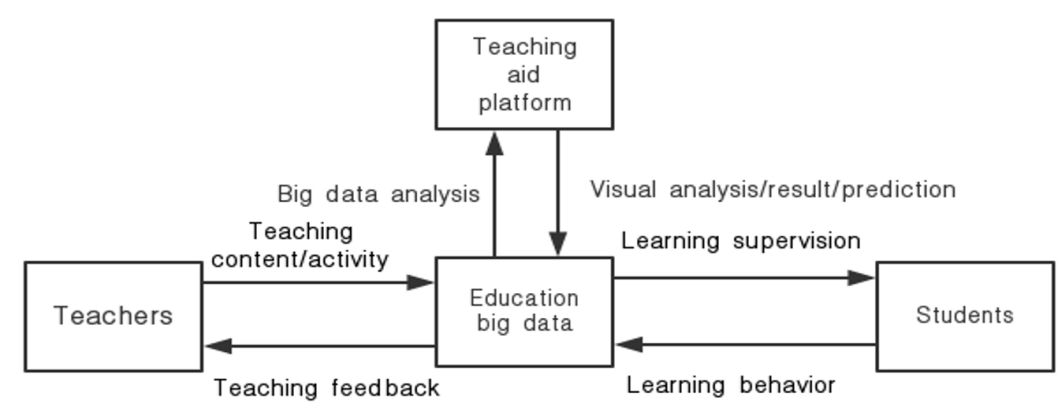

Fig. 1. Framework for the teaching design of college mathematics

With the help of education big data analysis methods, the teaching data can be identified and recognized as valuable information, such as student's mastery of a certain knowledge point, the learning early warning, etc., so as to provide more accurate, timely, and comprehensive supports for the teaching of teachers (such as adjust teaching progress, understand student's mastery of difficult and important knowledge 
points) and the learning decision of students (such as understand their own learning situations), and to promote individualized learning.

\subsection{Intelligent teaching platform}

The intelligent teaching platform is a support platform for the teaching design based on big data analysis, it provides teachers and students with the functions of assisted learning, management and services, realizes pre-class, in-class and after-class teaching communication and exchange, resource pushing, and information services, etc. Blackboard is a commonly used intelligent teaching platform in foreign countries, and domestic intelligent teaching platforms include the Rain Classroom, the Moso Teach, and the Chaoxing MOOC, etc.

Teachers' using of intelligent teaching platforms mostly stays in the signing-in, teaching resource publishing, and other simple functions. As for how to apply the intelligent teaching platform to student-teacher interaction, and how to design teaching activities to better understand the students' learning situations, it requires the teachers to invest more energies to learn about it.

\subsection{Classroom teaching process}

Applying big data analysis to the design of college mathematics courses requires teachers to change their educational philosophy. The performance of teachers and students in the classroom can be converted into data. However, only by the performance of students in the classroom, we can't make a comprehensive analysis on the students' achievements, we also need the data from after class. We divided the college mathematics classroom teaching process into three links: pre-class, in-class and afterclass. According to the three links, the teaching design processes are proposed as follows:

Pre-class: Teachers need to use tests or questionnaires to analyze the students' situations and design the teaching content to provide pre-study guidance for the students. The pre-study guidance includes teaching resource push, online resource link push, pre-study outline, pre-class test, discussion and other forms. Teachers can actively explore the flipped classroom and the blended teaching, master students' prestudy situations through intelligent teaching platforms and adjust their teaching content and lecture strategy.

In-class: Teachers need to complete the knowledge introduction according to the pre-class preparation situation and organize students to carry out learning discussion, and then supervise their learning effects via real-time exercises and tests, and draw conclusions and answer questions.

After-class: Teachers need to examine the students' learning effects via after-class assignments and exercises, give timely feedback on the common problems, and give guidance to students who have trouble in their studies.

The entire teaching process is student-centered and the teacher plays the role of a "scaffolding". All behavioral data of teachers and students in the three links will be recorded and feedback by the intelligent teaching platform. 


\subsection{Diversified assessment methods}

In the traditional college mathematics assessment methods, although every college has set the "usual performance", the evaluation of "usual performance" is often given by teachers according to the student's attendance and homework. The "usual performance" can't truly reflect the learning situation of every student, and for some students who have difficulties in their learning, their learning situation can't be reflected through usual performance. Now, with the help of intelligent teaching platform, every student's learning activities and behaviors can be recorded clearly, which provides a solid foundation for strengthening procedural management and realizing diversified assessment.

\subsection{Individualized education}

Under the traditional teaching method, the existing teaching takes a class as a unit. And the students' learning effects is usually measured by the average level, which can not represent the condition of each student. Education big data realizes individual sample collection and judgment, allowing teachers and students to understand more accurate details. By analyzing the learning behavior data of students, we can determine students' mastery of knowledge and predict their learning status. Especially for some students who have difficulties in learning, it could give warnings so that teachers can discover timely and give guidance accordingly, which improves the teaching effects of teachers and truly realizes teaching students in accordance of their aptitude.

\subsection{Teaching quality evaluation}

In traditional teaching, the evaluation of teachers' teaching is often determined by experts. The basis of judgment includes whether the teaching content is correct and complete, whether the classroom activity design can achieve the teaching goal, and whether the lecturing is logical or not. Experts rely on their own experiences to judge students' learning effects, and the feedback from students is often replaced by sampled data or even one-sided data. The education big data fed back through the intelligent teaching platform can truly reflect the teaching level and the workload of teachers. Using the platform, teachers and students jointly score each student's learning situation, and different learning procedures are assigned with different weights. The teaching quality of the course consists of teachers and students' teaching and learning data, peer review, expert evaluation and teaching self-evaluation. Different evaluators use different evaluation indicators, so as to truly reflect the learning effects of students and use the data to restore the classroom to the greatest extent. Education big data enables the students' experiences and feelings to be quantified, and students' requirements are revealed, thereby obtaining objective and real teaching quality evaluation of the courses. 


\subsection{Implementation effect analysis}

This paper takes Advanced Mathematics course of Beijing Institute of Petrochemical Technology as the research object, and the author is a teacher of Advanced Mathematics course in this school. The data of the 2017-2018 school year is adopted to prove that using the method based on big data to carry out Advanced Mathematics course reform is feasible. The intelligent education platform of this course is the Moso Teach. Figures 2-3 below are average score comparisons of Advanced Mathematics course of students in other classes of the school and the students taught by the author in 2017 fall semester (Volume I) and 2018 spring semester (Volume II), respectively. In the 2017 fall semester, there were 613 students who took Advanced Mathematics (Volume I) exam, and the number of students taught by the author was 58; in the 2018 spring semester, there were 618 students who took Advanced Mathematics (Volume II) exam, and the number of students taught by the author was 157 . It should also be noted that other teachers used the traditional teaching mode.

In order to examine the self-learning effects of students, the author conducted selfassessment questionnaire surveys on students' learning effect before and after the course of Advanced Mathematics. The survey content included the understanding of the development history of Calculus, the understanding of the respective characteristics of college mathematics and high-school mathematics, and the understanding of the contribution of Advanced Mathematics to their majors, all 15 questions. The options for each question were five-level: A (Strongly agree), B (Agree), C (Uncertain), $\mathrm{D}$ (Disagree), and E (Strongly disagree). For the two surveys, the questions were the same, and these questions were mainly used for examining the students' selfassessment of their learning effects. Figure 4 shows the survey results of the first question, it can be seen that, after the studying of the course, students' understanding of the history of Calculus had been improved. Table 1 shows the percentage of students who answered "agree" or "strongly agree" before and after class. Figure 5 shows the difference value about students' self-assessment before and after the course of Advanced Mathematics.

\section{Fail Rate}

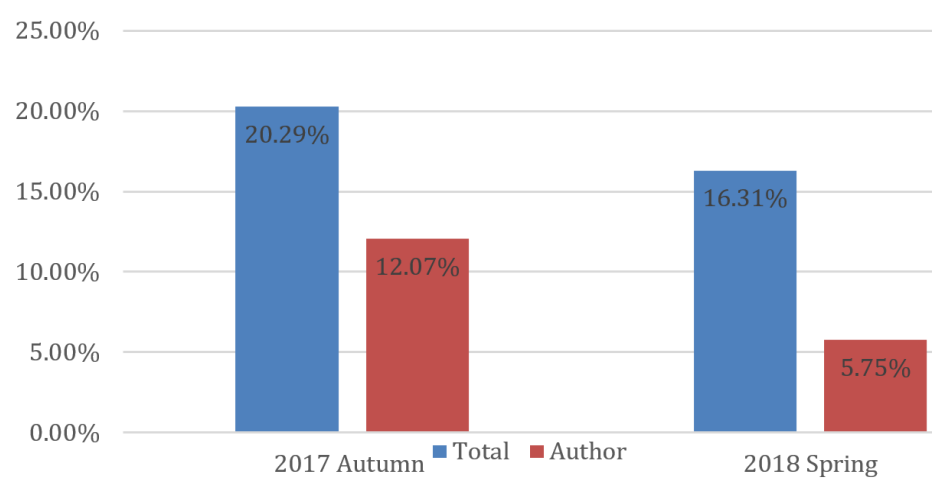

Fig. 2. Comparison of fail rates 


\section{The Average Score}

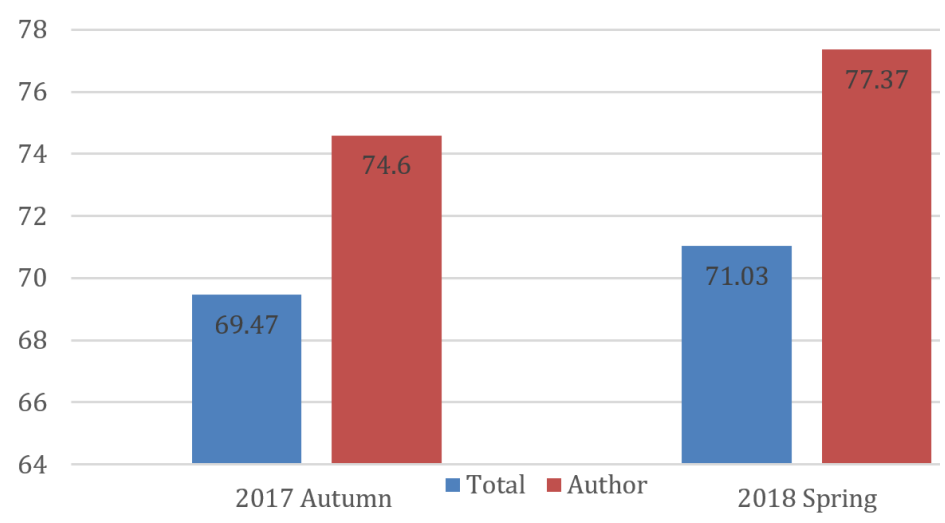

Fig. 3. Comparison of average scores

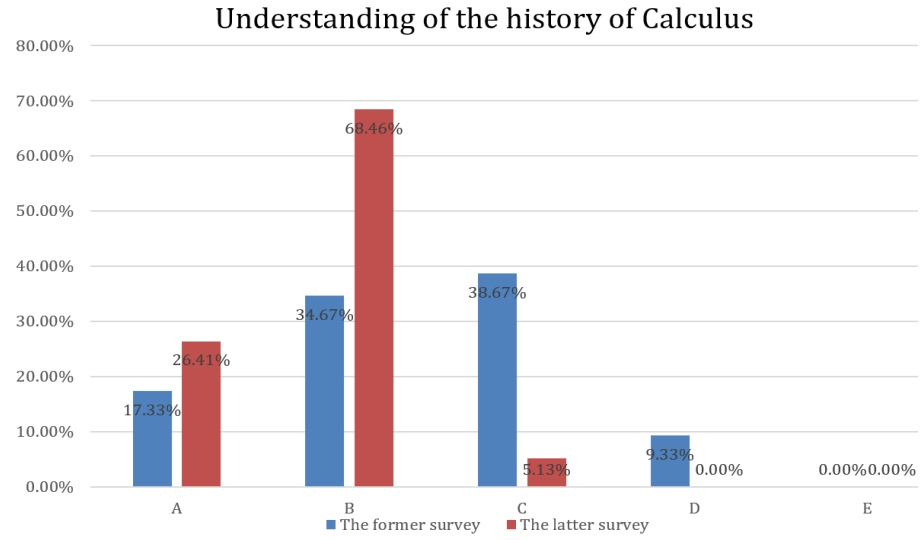

Fig. 4. Comparison of students' self-assessment results in the two surveys

We can see from Table 1 and Figure 5; students can improve the most in the selfevaluation of mastering some important ideas and methods of Advanced Mathematics. However, there is no improvement in the self-evaluation of students who can provide theoretical basis for controversial issues. In fact, there are some problems that cannot be effectively solved by only taking the course of advanced mathematics, but it is clear that our teaching is actually effective. 
Table 1. Self-assessment forms of students of advanced mathematics courses before and after class

\begin{tabular}{|c|c|c|c|}
\hline Questionnaire content & $\begin{array}{c}\text { The former } \\
\text { survey }\end{array}$ & $\begin{array}{l}\text { The latter } \\
\text { survey }\end{array}$ & $\begin{array}{l}\text { Difference } \\
\text { value }\end{array}$ \\
\hline 1. Understanding the development of calculus & $52.0 \%$ & $94.9 \%$ & $42.9 \%$ \\
\hline $\begin{array}{l}\text { 2. Understanding the different characteristics of college mathemat- } \\
\text { ics and middle and high school mathematics methods }\end{array}$ & $61.0 \%$ & $88.0 \%$ & $27.0 \%$ \\
\hline $\begin{array}{l}\text { 3. Understanding the Contribution of Advanced Mathematics to the } \\
\text { major }\end{array}$ & $50.6 \%$ & $74.7 \%$ & $24.0 \%$ \\
\hline $\begin{array}{l}\text { 4. Mastering some important ideas and methods of Advanced } \\
\text { Mathematics }\end{array}$ & $22.8 \%$ & $92.0 \%$ & $69.2 \%$ \\
\hline 5. Discovering and appreciating the value of mathematics & $27.9 \%$ & $56.0 \%$ & $28.1 \%$ \\
\hline $\begin{array}{l}\text { 6. Improving the thinking and logic training through the study of } \\
\text { Advanced Mathematics }\end{array}$ & $87.4 \%$ & $96.0 \%$ & $8.6 \%$ \\
\hline 7. Ability of critically analyzing and evaluating different arguments & $35.8 \%$ & $73.3 \%$ & $37.6 \%$ \\
\hline 8. Ability of accepting new ideas, theories and methods & $47.9 \%$ & $97.3 \%$ & $49.4 \%$ \\
\hline 9. Confidence of reading about science & $47.9 \%$ & $89.3 \%$ & $41.4 \%$ \\
\hline 10. Interest of natural science & $85.9 \%$ & $89.3 \%$ & $3.4 \%$ \\
\hline $\begin{array}{l}\text { 11. Importance of scientific knowledge to one's own intellectual } \\
\text { development }\end{array}$ & $96.2 \%$ & $100.0 \%$ & $3.8 \%$ \\
\hline 12. Ability of presenting a theoretical basis for a controversial issue & $74.4 \%$ & $76.0 \%$ & $1.6 \%$ \\
\hline $\begin{array}{l}\text { 13. Confidence of discussing Advanced Mathematics problems } \\
\text { with teachers and classmates }\end{array}$ & $40.5 \%$ & $77.3 \%$ & $36.8 \%$ \\
\hline 14. Ability of finding mathematical problems in life & $39.23 \%$ & $57.33 \%$ & $18.10 \%$ \\
\hline
\end{tabular}

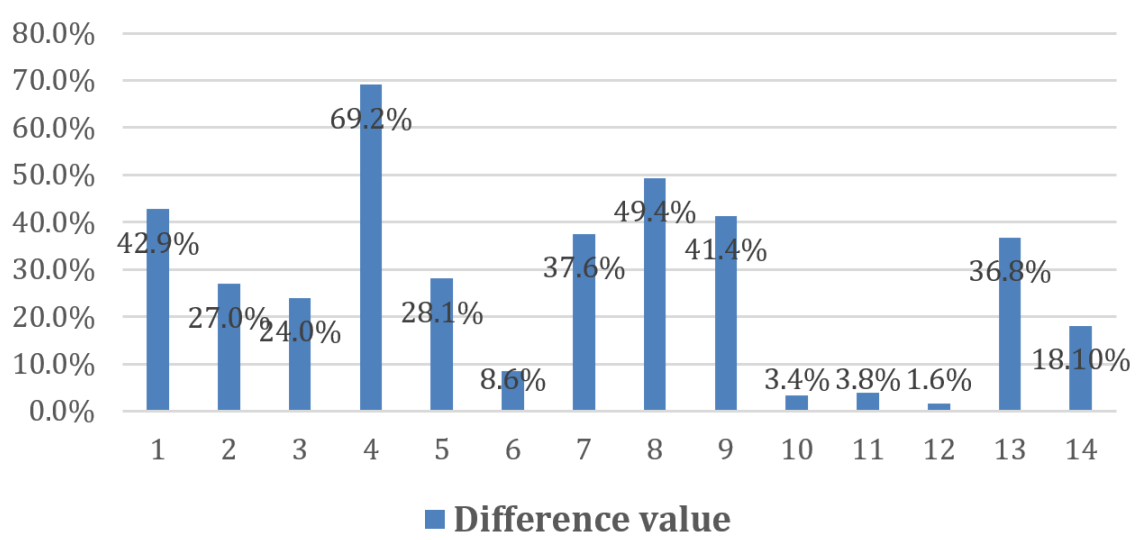

Fig. 5. Difference value of students' self-assessment before and after the course of Advanced Mathematics

From the above data, it can be concluded that the design of college mathematics teaching based on big data analysis can indeed improve the learning effects of students and the teaching effects of teachers. 


\section{$4 \quad$ Existing Problems and Prospects}

Although the design method of college mathematics teaching based on big data analysis has been proved to be effective, there are still some problems in this method. Firstly, teachers should comprehensively reform the current teaching methods, and redesign the teaching activities. The traditional teaching model is actually centered on teachers, classrooms and textbooks. This mode can be seen as that teachers teach teaching materials in the classroom; the core is the teacher. Now the teaching reform of "student-centered" has been vigorously carried out around the world [14-16]. Besides teachers' teaching, we can pay more attention to students' learning. Using the data of teachers' teaching and students' learning can better guide the teaching reform. For the teaching design based on big data, teachers need to invest more energy compared with the traditional mode of "lesson preparation-lecture-homework correction". And these workloads have not yet been recognized by various colleges, which has inhibited teachers' enthusiasm to participate in this work to some extent. Secondly, the intelligent teaching platform is not omnipotent. The existing platforms on the market have their respective advantages. Although the author had used the Moso Teach mostly, since the question bank of this platform can only identify choice questions, the author changed to the MAPLE T.A. for the online homework assignments and unit tests for students from fall 2018. And then the problem of data integration of different intelligent teaching platforms followed consequently. Finally, the users of education big data are not only experts in data processing, but also ordinary teachers mostly. Their demands for data analysis results are: simple, clear, and easy to use. Although the intelligent teaching management platform provides visual analysis and some data analysis, more in-depth data analysis requires teachers and teaching administrators to master some data analysis methods. But most of the teachers and teaching administrators lack abilities in this aspect, which also results in insufficient analysis despite the data is available, and causes a waste of data.

The era of big data has arrived, and the impact of big data on education and teaching reform is inevitable. The analysis and processing technologies that make data generate value has now become an important support for the theories of teaching and learning procedures. College mathematics teaching design based on big data analysis can customize the teaching through data, improving teachers' teaching quality and students' learning quality.

\section{Acknowledgement}

The authors would like to thank Beijing Municipal Education Commission Scientific Research Plan, Social Science Plan General Project for their financial support under the grant number of No. KM201710017004, and the Project of "Passing the Scientific Research" for the Young Teachers of Beijing Institute of Petrochemical Technology. The authors would like to thank 2015-2016 School Year Educational Teaching Reform and Research Key Projects of Beijing Institute of Petrochemical 
Technology: A new student-centered model of mathematics teaching based on the "Excellence Plan" of our school, under the grant number of No. ZD20160801.

\section{References}

[1] Mayer-Schönberger, V., Cukier, K. (2017). Big Data: A Revolution That Will Transform How We Live, Work, and Think. Hodder \& Stoughton General Division. https://doi.org/10.3233/ip-140322

[2] Branch, R.M., Kopcha, T.J. (2014). Instructional Design Models, Handbook of Research on Educational Communications and Technology. Springer New York, 607-615.

[3] Changwon, Y., Luis, R., Juan, L. (2014). Big data analysis using modern statistical and machine learning methods in medicine. International Neurourology Journal, 18(2): 50-57. https://doi.org/10.5213/inj.2014.18.2.50

[4] Ponsard, C., Touzani, M., Majchrowski, A. (2018). How to conduct big data projects: Methods overview and industrial feedback, Ingénierie des Systèmes d'Information, 23(1): 9-33. https://doi.org/10.3166/isi.23.1.9-33

[5] Fan, J.H. (2018). On computer and foreign language teaching and learning in Big Data era. International Journal of Emerging Technologies in Learning, 13(5): 236-245. https://doi.org/10.3991/ijet.v13i05.7717

[6] Huda, M., Maseleno, A., Shahrill, M., Jasmi, K.A., Mustari, I., Basiron, B. (2017). Exploring adaptive teaching competencies in big data era. Journal of Emerging Technologies in Learning, 12(3): 68-83. https://doi.org/10.3991/ijet.v12i03.6434

[7] Reddy, V.S., Rao, T.V., Govardhan, A. (2017). Data mining techniques for data streams mining, Review of Computer Engineering Studies, 4(1): 31-35. https://doi.org/10.18 280/rces.040106 Long, F. (2017).

[8] Yu, J., Wang, H. (2018). A deep neural network-based algorithm for safe release of big data under random noise disturbance. Ingénierie des Systèmes d'Information, 23(6): 189200. https://doi.org/10.3166/ISI.23.6.189-200

[9] Bala, M., Ojha, D.B. (2012). Study of applications of data mining techniques in education. Journal of Research in Science \& Technology, 1(4): 1-10.

[10] De Loor, P., Richard, R., Bevacqua, E. (2018). Evolutive body interaction between a human and a virtual character. Theoretical model proposition and evaluation within a fitness exergame. Revue d'Intelligence Artificielle, 31(5): 557-579. https://doi.org/10.3 166/RIA.31.557-579

[11] Hadioui, A., El Faddouli, N., Touimi, Y.B., Mohammed, S.B. (2017). Machine learning based on big data-extraction of massive educational knowledge. International Journal of Emerging Technologies in Learning, 12(11): 151-167. https://doi.org/10.3 991/ijet.v12i11.7460

[12] Liu, F.J. (2014). Research overview of the big data's application in education. Research Overview of the Big Data's Application in Education, 24(8): 13-19. https://doi.org/10.3969/j.issn.1009-8097.2014.08.002

[13] Meng, Z.Y., Lu, X., Hu, F.G. (2017). Theoretical path and application thinking on the realistic way of big data driven education: a review of the first Chinese education big data development forum. Journal of Distance Education, 35(2): 9-18.

[14] Zhao, J.M. (2016). On the new three-centered theory: concepts \& history. Research in Higher Education of Engineering, 3: 35-56.

[15] Zhao, J.M. (2017). Open the blackbox: the scientific foundation of undergraduate learning and development (part 1). Research in Higher Education of Engineering, 3: 31-52. 
[16] Zhao, J.M., Gao, X.H. (2017). On the Student-centered Undergraduate Education Reform. China Higher Education Research, 8: 36-40. https://doi.org/10.16298/j.cnki.1004$\underline{3667.2017 .08 .08}$

\section{Authors}

Limin Cui is currently a lecturer in the Department of Mathematics and Physics at Beijing Institute of Petrochemical Technology, China. She received the B.Sc. Degree in College of Science at Qiqihaer University, the M.Sc degrees in College of Science at University of Science \& Technology Beijing, and the Ph.D. degree in Computer Science at Hong Kong Baptist University. Her research focuses on machine learning, monifold learning and wavelet analysis. She has been teaching university mathematics courses, including Advanced Mathematics, Linear Algebra, Probability Theory and Mathematical Statistics. She also served as Vice Dean of the department. In order to improve the learning effect of students, she has been trying to implement teaching reform.

Yonglong Liao is currently a lecturer in the Department of Mathematics and Physics at Beijing Institute of Petrochemical Technology, China. He received the B.Sc. Degree in Mathematics and Applied Mathematics from Tangshan Normal University, and the Ph.D. degree in General Mechanics and Mechanics Foundation at University of Science \& Technology Beijing. His research interests include preview control and delay systems. He has been teaching university mathematics courses, including Operations Research and Optimization, Linear Algebra, Probability Theory and Mathematical Statistics.

Ying Wang is a lecturer in the Department of Mathematics and Physics at Beijing Institute of Petrochemical Technology, China. She received the Ph.D. Degree from the School of Mathematics and Statistics at Central South University. Her research focuses on random process. She is interested in instructional design.

Xiaoyan Dong is currently an associate professor in the Department of Mathematics and Physics at Beijing Institute of Petrochemical Technology, China. She received the B.Sc. Degree and the M.Sc degree in College of Mathematics at Northwest Normal University . Her research focuses on improving the learning effect of students. She has been teaching university mathematics courses, including Advanced Mathematics, Probability Theory and Mathematical Statistics.

Article submitted 2019-04-18. Resubmitted 2019-05-27. Final acceptance 2019-05-27. Final version published as submitted by the authors. 